7. Preventing norovirus infection. Centers for Disease Control and Prevention website. https://www.cdc.gov/norovirus/about/prevention.html. Published 2018. Accessed 19 July, 2018.

8. Tung G, Macinga D, Arbogast J, Jaykus L. Efficacy of commonly used disinfectants for inactivation of human noroviruses and their surrogates. J Food Prot 2013;76:1210-1217.
9. Cromeans T, Park GW, Costantini V, et al. Comprehensive comparison of cultivable norovirus surrogates in response to different inactivation and disinfection treatments. Appl Environ Microbiol 2014;80:5743-5751.

10. Kniel KE. The makings of a good human norovirus surrogate. Curr Opin Virol 2014;4:85-90.

\title{
Patients as stakeholders: Developing a patient-centered healthcare epidemiology research agenda
}

\author{
Julie A. Keating $\mathrm{PhD}^{1}$, Nicole Brys $\mathrm{MPH}^{1,2}$, Mary Jo Knobloch PhD, $\mathrm{MPH}^{1,2}$ and Nasia Safdar MD, $\mathrm{PhD}^{1,2}$ \\ ${ }^{1}$ William S. Middleton VA Hospital, Madison, Wisconsin and ${ }^{2}$ Division of Infectious Diseases, Department of Medicine, University of Wisconsin-Madison, Madison, \\ Wisconsin
}

To the Editor-Due to its many benefits, stakeholder engagement in health research has been increasingly prioritized in recent years. $^{1-9}$ Engagement throughout the research cycle, from idea development through dissemination of results, helps to ensure

Table 1. Patient-Perceived Implementation Barriers to HAI Prevention Strategies

\begin{tabular}{|c|c|c|}
\hline Prevention Strategies & Individual-Level Barriers & Provider- and Institutional-Level Barriers \\
\hline \multicolumn{3}{|c|}{ 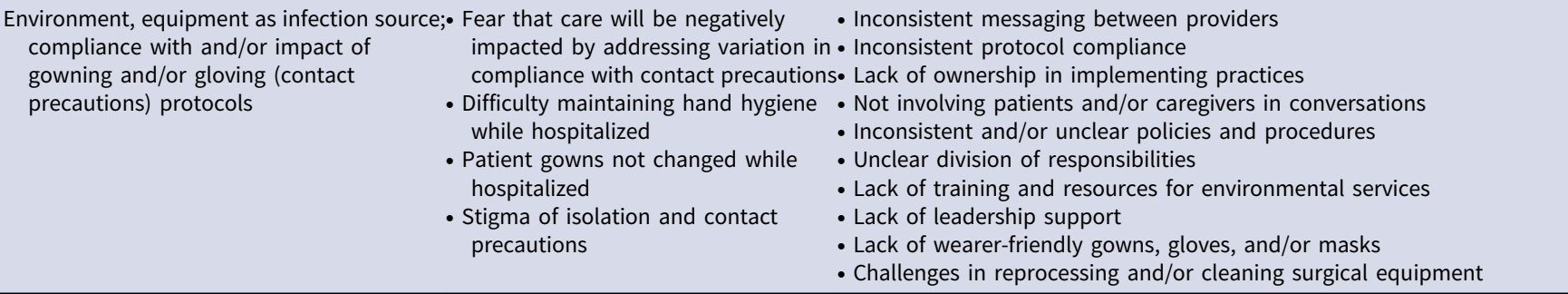 } \\
\hline $\begin{array}{l}\text { Presurgical preparation (CHG bathing, } \\
\text { Staphylococcus aureus testing, lifestyle } \\
\text { changes) }\end{array}$ & $\begin{array}{l}\text { - Lack of education about preparation } \\
\text { for surgery and the risks of not } \\
\text { preparing } \\
\text { - Variation in procedural information } \\
\text { - Variation in products and use } \\
\text { - Not preparing for surgery }\end{array}$ & $\begin{array}{l}\text { - Inconsistent messaging between providers } \\
\text { - Inconsistent provider involvement } \\
\text { - Lack of access and/or encouragement to learn best practices } \\
\text { - Variation in evidence for and priority of practices } \\
\text { - Variation in practices and policies } \\
\text { - No standardized CHG dilution methods } \\
\text { - Lack of support to implement new practices }\end{array}$ \\
\hline $\begin{array}{l}\text { Laboratory testing and antimicrobial } \\
\text { stewardship }\end{array}$ & $\begin{array}{l}\text { - Belief that antibiotics are always } \\
\text { helpful } \\
\text { - Variation in insurance coverage for } \\
\text { therapies } \\
\text { - Not discussing therapeutic choices } \\
\text { with providers } \\
\text { - Lack of education and/or } \\
\text { understanding about antibiotic } \\
\text { reason, use (ie, frequency and } \\
\text { duration), and side effects } \\
\text { - Distrust of new therapies }\end{array}$ & $\begin{array}{l}\text { - Overtesting } \\
\text { - Lack of procedures to stop antibiotic course based on test results } \\
\text { - Impacts of patient-reported allergy to prescription (without documented } \\
\text { allergy testing) } \\
\text { - Fear of negative rating from patient for not prescribing an antibiotic } \\
\text { - Inconsistent messaging between providers } \\
\text { - Formulary restrictions } \\
\text { - Limited research and/or education on new evidence-based practices and } \\
\text { alternatives (eg, probiotics) } \\
\text { - Lack of educational outreach in community } \\
\text { - Impact of telemedicine } \\
\text { - Reimbursement policies } \\
\text { - Underusing and/or excluding pharmacists on patient care team } \\
\text { - Antifungals and/or antivirals not included in stewardship } \\
\text { - Lack of standardized scripts for supplies }\end{array}$ \\
\hline
\end{tabular}

Note. HAI, healthcare-associated infections; CHG, chlorhexidine gluconate.

Author for correspondence: Julie Keating, William S. Middleton Veterans Hospital, 2500 Overlook Terrace, Madison, WI, USA 53705. E-mail: julie.keating@va.gov

Cite this article: Keating JA. et al. (2018). Patients as stakeholders: Developing a patient-centered healthcare epidemiology research agenda. Infection Control \& Hospital Epidemiology 2018, 39, 1389-1390. doi: 10.1017/ice.2018.214 that research questions and outcomes are meaningful and relevant to stakeholders, ${ }^{3,4}$ and it may also improve research quality and appropriateness. ${ }^{4-6,9}$ 
Given the threat of healthcare-associated infections (HAIs) to patient safety, ${ }^{10}$ stakeholder engagement is critical in healthcare epidemiology. Effective HAI prevention and control require collaboration between multiple stakeholders: clinicians, other providers directly or indirectly involved in patient care, healthcare administrators, caregivers, and patients. Despite progress in understanding pathogens, epidemiology, and prevention and control mechanisms, many research gaps remain. ${ }^{10}$ Because patients and caregivers have not previously been involved as stakeholders in HAI research, their perspectives on these gaps are poorly understood. We believe that increasing the engagement of patients and caregivers in HAI research is necessary to address existing gaps in knowledge related to HAI prevention.

To develop a patient-centered HAI research agenda, we convened a patient and caregiver stakeholder (PCS) group of 7 older adults ( 4 men, 3 women, most $>50$ years old) from Wisconsin. All members had experience as a patient or as a caregiver to a patient with an HAI, and 2 members had additional professional medical experience. Before discussing the research agenda, the PCS group members received initial training in HAI research, terminology, and concepts, and they participated in preparatory activities such as describing their perceptions of environmental contamination in a hospital room and meeting with institutional stakeholders to discuss HAI work.

Research agenda discussions centered on a subset of strategies identified by the Society for Healthcare Epidemiology of America $(\mathrm{SHEA})^{10}$ : (1) evaluation of environment and equipment sources for infection; (2) compliance with and impact of contact precautions; (3) patient presurgical preparation; and (4) antibiotic stewardship, particularly the role of pharmacists. In consultation with the Wisconsin Network for Research Support (www.winrs.nursing.wisc.edu/), we designed an activity for stakeholders to identify their perceived individual (patient and/or caregiver) and provider- or institutional-level barriers to implementing a strategy. Their ideas were elaborated through discussions with the research team, and the resulting barriers represent potential targets for intervention in future patientcentered HAI research (Table 1).

Patient feedback provides important context to previously described HAI prevention research topics. ${ }^{10}$ For example, patients highlighted concern that care may be negatively impacted by asking providers about noncompliance with contact precaution protocols. While HAI research is often focused within healthcare settings, patients wanted to know the steps they could take outside the healthcare setting to reduce their risk of acquiring HAIs. However, the demographics of the PCS group may limit the generalizability of these results to other patient populations.

These perspectives have been critical as we identify priority areas for investigation and as we engage patients in developing research projects to address these areas. We encourage other researchers to consult with patients and caregivers in setting their research agendas and to develop a patient-centered plan aligned with the needs of those who know the most about living with an HAI.

Acknowledgments. The views in this article are those of the authors and do not necessarily represent the position or policy of the Department of Veterans Affairs or the United States government. The Wisconsin Network for Research Support aided in editing the manuscript.

Financial support. This work was supported by the Department of Veterans Affairs Quality Enhancement Research Initiative program (grant no. PEC 15248) in partnership with the VA National Center for Patient Safety, and it was partially funded through a Patient-Centered Outcomes Research Institute Eugene Washington Engagement Award (grant no. 2680-UWisc).

Conflicts of interest. All authors report no conflicts of interest relevant to this article.

\section{References}

1. Mackie IT, Sheldrick CR, De Ferranti DS, Saunders GT, Rojas KE, Leslie KL. Stakeholders' perspectives on stakeholder-engaged research (SER): strategies to operationalize patient-centered outcomes research principles for SER. Med Care 2017;55:19-30.

2. Fleurence R, Selby JV, Odom-Walker K, et al. How the Patient-Centered Outcomes Research Institute is engaging patients and others in shaping its research agenda. Health Aff (Millwood) 2013;32:393-400.

3. Forsythe L, Heckert A, Margolis MK, Schrandt S, Frank L. Methods and impact of engagement in research, from theory to practice and back again: early findings from the Patient-Centered Outcomes Research Institute. Qual Life Res 2017;27:17-31.

4. Jagosh J, Macaulay AC, Pluye P, et al. Uncovering the benefits of participatory research: implications of a realist review for health research and practice. Milbank Q 2012;90:311-346.

5. Brett J, Staniszewska S, Mockford C, et al. Mapping the impact of patient and public involvement on health and social care research: a systematic review. Health Expect 2014;17:637-650.

6. Brett J, Staniszewska S, Mockford C, et al. A systematic review of the impact of patient and public involvement on service users, researchers and communities. Patient 2014;7:387.

7. Concannon TW, Fuster M, Saunders T, et al. A systematic review of stakeholder engagement in comparative effectiveness and patient-centered outcomes research. J Gen Intern Med 2014;29:1692-1701.

8. Shippee ND, Domecq Garces JP, Prutsky Lopez GJ, et al. Patient and service user engagement in research: a systematic review and synthesized framework. Health Expect 2015;18:1151-1166.

9. Domecq JP, Prutsky G, Elraiyah T, et al. Patient engagement in research: a systematic review. Acta Veterinaria Scand 2014;14:89.

10. Safdar N, Anderson DJ, Braun BI, et al. The evolving landscape of healthcare-associated infections: recent advances in prevention and a road map for research. Infect Control Hosp Epidemiol 2014;35:480-493. 